Some new relationships

\title{
Medical Care and Health Education
}

\author{
LESTER BRESLOW, M.D., M.P.H.
}

$\mathrm{D}^{\mathrm{a}}$ OROTHY NYSWANDER in her own work focused attention on health education as a force in the dynamic social processes of the day. Therefore it seems appropriate to devote this year's lecture in her name to the relationship of health education to a current dynamic social process affecting health, namely the changing organization and delivery of medical care.

During the past 18 months the United States has made the most significant advances in medical care in several decades. Persons with a sense of history are already debating whether Medicare will prove as far reaching as Medicaid, or whether the Regional Medical Program for Heart Disease, Cancer, and Stroke will be more important. The potential of the new program for comprehensive health planning may outrank that of the other programs mentioned.

In the United States we have finally crossed the divide in the history of medical care. Momentous changes are actually taking place in the medical care system; they are not simply being discussed and wished for.

\section{Federal Participation in Health Care}

Incorporating medical care into the national social insurance program and committing Federal funds on a large scale to help pay for health care of the poor have attracted substantial attention. Beyond the fundings, and perhaps more fundamental, is the considerable emphasis on the nature and quality of care to be provided. Some effort has been initiated to improve the organization of care, for example, in the neighborhood health centers supported by the Office of Economic Opportunity. In this sense, not only has the United States begun to use a fiscal mechanism that has been in vogue among most other Western countries for many years, but we as a nation also have started to inject the U.S. propensity for organization into the health care system.

These many changes are taking place in medical care during a short period. Perhaps the underlying factor in these changes is that medical care is becoming important for health.

A half century or so ago, it was said, the average person encountering the average physician stood about a 50-50 chance of benefiting from the encounter. Contrary to that era, today it is clear that medical care can save lives and prevent much disability. This greater effectiveness of medical care, rather than its economic or other aspects, appears to be leading the American people to assert that good medical care should be available to all.

In response to this increasing value attached to health service, the nation has undertaken to remove the financial obstacles that formerly kept a portion of the population from obtaining care when they needed it. Medicare makes medical care financially attainable for persons over 65 years of age, and Medicaid does the same for persons receiving public assistance-in California about 5 percent of the State's population.

Dr. Breslow, now professor of public health at the University of California, Los Angeles, was director of the California State Department of Public Health. This paper is based on the eleventh annual Dorothy B. Nyswander Lecture at the University of California School of Public Health, Berkeley, October 13, 1967. 


\section{Lack of Coordination Among Services}

Concomitant with attention to financing health services, actions are being taken to improve the organization of health care to make it more orderly, flexible, and pertinent. Heretofore, the medical profession and the allied health professions have produced some really excellent "pieces" of medical care. Paradoxically, a major drawback has been the lack of cohesion: there are too many pieces which do not fit together well.

A California physician recently told me about the experience of a young mother in obtaining care for her child with multiple severe handicaps as a result of German measles in the mother during pregnancy. The birth of this severely handicapped child was the first evidence that health care was not well provided; therapeutic abortion would have avoided the problem.

Shortly after birth, a physician noted that the child was blind and recommended that the mother consult an ophthalmologist. This specialist, in turn, referred the mother to another ophthalmologist who was able to provide care through a program on which the first ophthalmologist did not serve. An operation at the age of 10 months was recommended. Before that time physicians at another hospital detected evidence of structural defects in the heart and referred the child for further diagnostic study of that organ.

Because none of the physicians already involved paid attention to the mother's observation of poor hearing, she took the child to a hearing center. The visit to the hearing center, not connected with any of the previous elements of care, led to the diagnosis of a serious hearing defect.

Not surprisingly, the mother was having difficulty with the child's nutrition. For this problem she received absolutely contradictory advice from two different medical sources.

The wonder is that the mother persisted in seeking care from this "mixed bag" and endeavored to put it together in a meaningful way. When asked her main difficulty, the mother responded that it was to get a babysitter so she could get away for a few hours. The mother also indicated that she needed help in deciding which medical appointments should take priority.

Steps are being taken to overcome this chaotic affluence of pieces of specialized medical care to achieve a more coherent system. For example, two regional diagnostic and counseling centers for the mentally retarded in California, and more to be established, bring together all resources-professional societies, voluntary health organizations, official health agencies, and others-previously sought out in a fragmented way by parents with a mentally retarded child. These new diagnostic and counseling centers are located in medical centers with access to any service that may be needed - even social and educational services - to meet all problems accompanying the mental retardation.

Access to any required institutional or other services is assured by State funds made available to the centers to purchase needed service in the community. These centers are typical examples of recent efforts to improve the organization of health services.

\section{Changing Concepts of Health Education}

Changes have been occurring also in health education. One set of changes appears to have emerged from the frustrations of health educators in certain medical care programs. The mass campaigns of the past few decades-chest $\mathrm{X}$-ray surveys, immunization programs, and others-brought at most about an 85 percent response among residents of a community. While such a response was high in certain respects, it was exasperating constantly to find that at least 15 percent of the persons would resist the appeals. Often these were the persons most in need of the service.

As health professionals, our first reaction to rejection of our valuable advice was to invent some bad words to describe the people who apparently did not trust us. We called them names like "hard core." Then, the more sophisticated among us discovered a marvelous weapon, motivational research. The very term prompted good feelings in us, since it seemed to make health educators something of a bridge between psychology and sales management. It brought health educators close to using fancy packaging as a means of overcoming "sales resistance."

More recently, society has begun to appreciate that conditioning by experience determines behavior and that health educators must come to grips with this aspect of people's lives if 
influence on health behavior is to be achieved. How people are treated by physicians and policemen affects their further response to such societal helpers. Consequently, before the still fluid medical care situation solidifies, there is an opportunity to consider just how health education should relate to medical care.

\section{Imparting Information to the Public}

First, knowledge still appears to be a significant influence on behavior with respect to using medical care. In a field where such terms as "state of readiness," "peer group," and "value system" are accepted by many as the hallmark of sophistication, I hope it will not be regarded as old fashioned to emphasize that imparting knowledge is one objective of health education. The fundamental importance of this objective may have been obscured temporarily by more recent emphases on various aspects of motivation.

For example, in a study of who used the cytology test for cancer (Papanicolaou smear), women most in need of the test from the standpoint of frequency of the disease-those in the lowest social class-used it the least (1). Among women in Alameda County in 1962, only 36 percent of those married to laborers and service workers had received the test compared with the 60 percent of those married to men in the professional and managerial class.

However, about two-thirds of the women in every social class who said that they had heard of the test also reported that they had received it. Thus, the factor affecting all social classes about equally appeared to be the knowledge that there is such a test. Similarly, knowledge about the existence of artificial immunization against certain communicable diseases is a highly significant factor in obtaining such immunization.

Health education has a vital role in distributing knowledge about what medical care can accomplish. This function is much underestimated.

\section{Bringing Health Services and Users Together}

A second way in which health education should relate to medical care is to assist people in establishing a connection with the health care system. Many features of life in the United States militate against such a connection. The financial barrier has been important for some people, but it is being rapidly overcome.

Probably a substantial deterrent is the chaotic nature of the health care system itself. Various medical specialists, other kinds of health care personnel, and health facilities are not well related functionally to one another. Whether to seek health advice from a pharmacist, a physician, or a clinic is by no means clear to many persons in our society. The patient with a complicated problem may have serious difficulty finding his way through the maze of health care services.

Another deterrent is the mobility of the U.S. population. Data from the U.S. Census indicate that 20 percent of the population moves in any given year and that one-third of the movers go to another county. Often these moves are not just geographic; they may impose changes in conditions of life and exposure to different community mores.

The fragmented nature of the health care system and the mobility of the population make it doubly difficult, especially for some persons, to establish a good connection with the health care system. In each community, health education is needed to help new arrivals as well as those who have lived there for some time use health care resources advantageously. This facet of health education, incidentally, is often stressed by physicians who see the unfortunate results of patients' bewilderment in seeking care.

An obvious response to this situation by health educators has been to ask physicians why they do not organize health care into a better system. Actually, increasing numbers of physicians are trying to do just that and, again, they need help from those trained in health education.

It is becoming increasingly clear that for certain segments of the population the old arrangements for medical care do not suffice. For example, agricultural workers and their families who follow the crops, living in communities remote from physicians' offices or hospital clinics, find lack of transportation and time off from work serious deterrents to obtaining medical care. Even in the cities, sizable numbers of people are often, in effect, isolated from health care resources.

These circumstances have led health depart- 
ments, medical schools, county medical societies, hospitals, and other agencies to organize new types of medical services that are really accessible. Innovations in service organization such as night-time field clinics and comprehensive neighborhood health centers are emerging throughout California, as elsewhere in the country. In Watts and East Los Angeles, San Francisco, East Palo Alto, and more than 20 rural counties, programs have begun during the past few years to meet the specific needs of groups formerly disenfranchised from the benefits of modern health care.

Experimentation with new forms of organization of health services is just gaining momentum. Health educators can be a potent force alongside physicians, health officers, and others in preparing the community to accept these new endeavors and in aiding the development of specific projects.

In reorganizing services it is important to avoid being doctrinaire about the particular form of service needed, to enlist the ideas and participation of persons to be served, and to work patiently with practitioners accustomed to older patterns of care. In these respects, health educators are well qualified to assist. They can be a considerable force in the reorganization of health services-a task which is already engaging the efforts of many leading professionals in medicine, medical education, and health administration.

Health education has a potentially strong role not only in helping people understand what the health care system can do but also in helping them establish a connection with that system. The educators can also help modify the system so that it is more responsive to the needs of people.

\section{Teaching Adjustment to Chronic Illness}

In addition, health education should assist the increasing numbers of persons who must adapt their lives to chronic illness. Consider the hundreds of persons who must have kidney dialysis two or three times a week. The patients are literally kept alive week after week by the artificial kidney. Consider further the tens of thousands of persons who have been treated for cancer and survived 10 days or 10 months or
10 years, and the changes these time periods bring. Consider also the hundreds of thousands of persons whose daily routines must be adapted to living with heart disease.

Only a few decades ago, before chronic illnesses had become a major health problem and certainly before the medical profession had begun to deal with them effectively, the adjustment of patients to life limited by such health conditions did not trouble us. Very few were affected. Now, rather suddenly, masses of people face years of living with a physical or mental handicap.

The remarkable resiliency of human beings in adapting to handicaps has tended to submerge this problem. However, if education is viewed as life preparation, then health education in this era must concern itself with helping people adjust to varying degrees of chronic illness in themselves and their families. So far, this task has fallen largely to physicians and social workers working with individual patients, and such work obviously must continue. But adjustment to chronic disease is becoming more and more a community problem suitable for analysis and attack by means of health education.

\section{Influencing Formation of Personal Habits}

Considering how health education relates to medical care also requires noting that good use of medical care is only one way in which health education can influence behavior that will bring better health. Undoubtedly more significant is the influence health education can have on people's daily habits. Personal patterns of using alcohol, tobacco, and drugs, driving automobiles, eating, and exercise affect man's health far more than physicians can influence it.

Self-control was a popular idea a few decades ago; it is somewhat neglected now, but will be required more than ever in what has come to be called "the affluent society." Perhaps, the term "self-control" is out of fashion and will never be popular again. The practice of something like it, however, is essential to good health when food, liquor, cigarettes, and automobiles are so widely available and physical demands on their users so minimal.

How man uses these "good things of life" determines his health far more completely than 
all the work physicians can do. Helping people live in this situation is a major task of health education in this era, both in this nation and in other countries, especially those developing ways of life that are common in the United States. The fact that medical care is momentarily attracting so much attention should not distract persons concerned with health education from this more fundamental point.

\section{Conclusion}

Because medical care is becoming more effective and more available, the need for close collaboration between health education and medical care is great. To enable people to gain the most from the evolving medical care system, health education should popularize what medical care can really do and combat misguided expectations. Health education should aid people in making an effective connection with the medical care system and in changing the system to make it more coherent and pertinent to their needs.

As medical care becomes more concerned with chronic illness, health education should help create a community climate suitable for wholesome adaptation of disabled persons. Most important, as medical care takes the limelight in health affairs, health education should continue to concentrate on its primary mission-influencing people to order their daily lives in ways that are conducive to good health.

\section{REFERENCE}

(1) Breslow, L., and Hochstim, J. R. : Sociocultural aspects of cervical cytology in Alameda County, Calif. Public Health Rep 79: 107-112, February 1964.

\section{HEW Staff Appointment}

William H. Mitchel, Ph.D., has been appointed Deputy Assistant Secretary for Management Systems. He will supervise the development of all organization and management systems designed to implement the Department's policies and programs.

Dr. Mitchel's responsibilities will include direction of the existing Office of Management Systems and Office of Management Planning. His group will emphasize the extension of modern management technologies, such as those based on the computer sciences, to improve departmental efficiency in data processing, data communications, and management systems. He will have overall departmental responsibility for organization planning and control, management appraisal and improvement, and management studies and consultation.

Before his appointment with the Department, Dr. Mitchel was on the faculty of the University of Southern California. He was director of two major projects-investigation of the application of computer technology and the systems approach to the solution of urban problems-in the School of Public Administration. The projects were focused primarily on improving decision making procedures in a municipal environment.

Dr. Mitchel, a native of Oakland, Calif., headed the computer sciences laboratory at U.S.C. from 1963 to 1966. Prior to that he was director of the computer center, Emory University, Atlanta, Ga. He served with the Air Force Logistics Command's Sacramento Air Materiel Area from 1956 to 1962 as director of Data Systems Division and later as a tech. nical associate in the division.

Dr. Mitchel is a Navy veteran of World War II. He received his doctorate in public administration from U.S.C. last year. He holds bachelor's and master's degrees in political science from the University of California at Berkeley. He is a member of Phi Beta Kappa, the American Society of Public Administration, and the American Academy of Political and Social Sciences. 
RICE, DOROTHY P. (Social Security Administration): Current data from the Medicare program. Public Health Reports, Vol. 83, September 1968, pp. 719-730.

During the first year of Medicare (July 1966-June 1967), the Social Security Administration paid out about $\$ 3.2$ billion in benefits- $\$ 2.5$ billion in hospital insurance benefits under part $A$ and $\$ 700$ million in supplementary medical insurance benefits under part $B$. For each enrollee aged 65 and over, part $A$ benefit payments averaged $\$ 135$ and part B payments averaged $\$ 40$.

Most of the part A payments were for hospital care. Of the 19 million persons aged 65 and over enrolled in the program, about one in every five received hospital care during the first year of Medicare and stayed an average of $2 \frac{1}{2}$ weeks in the hospital. About one of 12 of these hospitalized persons went on to an extended care facility. Under part B, about onethird of the enrollees used covered services during each of the first 12 months of Medicare. By the end of the first 6 months of 1967 , about 5 million enrollees (44 percent) had incurred sufficient charges to meet the $\$ 50$ deductible and be eligible for benefits.

Other data available on the first year of Medicare include the following: (a) admission rates for hos- pitals and extended care facilities and rates for start of care for home health services, reported by State; (b) the number of claims approved for payment and the amounts reimbursed for each type of part A service and the number of reimbursed bills and reasonable charges for each type of part $B$ service; and (c) utilization and charges data from the part $B$ sample of the Current Medicare Survey, reported for each month and summarized for the two 6-month periods. The utilization and charges information includes the number of enrollees using services and the number meeting the deductible as well as total charges and the amounts potentially reimbursable.
BIERMAN, PEARL (Public Health Service), MYERS, BEVERLEE A., RODAK, JOHN, and REIBEL, JAY S.: Certifying independent laboratories under Medicare. Public Health Reports, Vol. 83, September 1968, pp. 731-739.

When Medicare began in July 1966 only six States, New York City, and Puerto Rico required independent laboratories to have some form of licensure. Since then additional States have passed licensure laws and more are formulating such legislation.

An initial requirement for participation in Medicare was that a laboratory director could not possess less than a bachelor's degree in a pertinent laboratory science, and that directors with less than a doctorate could only participate until June 30, 1971.

The regulations, however, were revised to permit nondegree directors to qualify their laboratories for coverage under Medicare if they passed a Public Health Service-sponsored examination. The examination contains a general section and sections on microbiology, clinical chemistry, hematology, blood grouping and $\mathrm{Rh}$ typing, and serology.

of more than 2,500 independent laboratories initially surveyed for Medicare, more than 500 laboratory directors could qualify only by taking at least one section of the examination. Of the 457 directors who actually took the initial examination, nearly 91 percent took the clinical chemistry section. A total of 70 failed to qualify their laboratories for coverage.

As of October 20, 1967, a total of 2,527 laboratories had been approved and 200 denied coverage. Of the laboratories approved, 95 percent reported performing tests and procedures in clinical chemistry. The percentages of laboratories performing tests in other specialties were serology, 85 ; microbiology, 81 ; im- munohematology, 64 ; exfoliative cytology, 41; and tissue pathology, 35.

Data available for 2,087 of the approved laboratories indicated that about 80 percent had supervisors other than the director. One-third of these had pathologists, 66 percent of whom were either board certified or board eligible in both anatomical and clinical pathology. Another third reported having supervisors qualified by at least a bachelor's degree with some graduate study (but not a master's degree), and some 16 percent had supervisors without a bachelor's degree.

To assure continuing good quality services of independent laboratories once they are approved for coverage under Medicare, Federal guidelines for evaluation of performance are being developed and States are being assisted in establishing proficiency testing programs. To be eligible for continued coverage under Medicare after that date, all laboratories will be required to participate in these State programs. 
AABERG, T. M. (University of Oklahoma Medical Center), NOZIK, R. A., and BRYAN, P. C. : Ongoing glaucoma detection program in Oklahoma. Public Health Reports, Vol. 83, September 1968, pp. 771-776.

An ongoing, statewide glaucoma detection program has been in operation in Oklahoma for 3 years. Individual screening clinies are located in county health departments and operated by public health nurses. Based on results of Schiotz tonometry, patients are divided into referral, borderline, and negative groups. The borderline groups are rechecked every year and the nega- tive groups every 2 years. Of 9,646 persons screened to date, 1.6 percent were given a confirmed or pending diagnosis by the referral ophthalmologists.

Secondary glaucoma evaluation was implemented recently in order to lower the false positive referral rate. A Glaucoma Evaluation Center was established for this purpose. Located at the University of Oklahoma
Medical Center, the evaluation center functions jointly with the university and the State health department.

A tonographic evaluation of the referral criteria used in the program demonstrated that 43 percent of 54 consecutively referred patients were more than 2 standard deviations from the mean level ; that is, the referrals were justified. This correlates well with the fact that 41 percent of the 54 referred patients were found to have clinical evidence of glaucoma on subsequent ophthalmological evaluation.
FENDALL, N. R. E. (The Population Council, New York City) : Dental manpower requirements in emerging countries. Public Health Reports, Vol. 83, September 1968, pp. 777-786.

The training and use of dental auxiliaries in newly emerging countries are proposed as the solution in such countries to the prevalence of dental disease, the paucity of professional dentists and dental schools, and the competing demands on their economies.

Statistically valid dental health surveys of many countries do not exist, but scattered evidence from Jamaica, Guatemala, Thailand, Senegal, and Kenya, among others, indicates that caries and periodontal infections are widespread, and malocclusion, malignant neoplasms of the mouth, and calcium defects are not infrequent. The ratio of dentists to population varies from 1

to 15,000 in Jamaica to 1 to 250,000 in Kenya.

Only 130 to 150 dentists are graduated each year from Africa's seven dental schools; half the countries of the world have no dental school and no prospects of attaining one. The cost of producing one professional dentist is prohibitive-\$23,000 per dentist in Guatemala, for example.

Auxiliaries can fulfill many basic dental needs of both children and adults in these countries. A program with three consecutive but overlapping phases is suggested. Phase one is to produce a small corps of superbly trained dentists. Phase two is to supplement this corps by giving existing paramedical and auxiliary health personnel 6 weeks of practical chairside training to increase out. reach. Phase three is to develop specific cadres of trained dental auxiliaries.

Single skill auxiliaries can be trained in 2 years. A dental surgeon and six such auxiliaries can serve an estimated 25,000 persons. Multiple skill auxiliaries with 8 years of general education need 3 years of technical training, preferably in an institution where graduate dentists and dental hygienists are also prepared.

The auxiliary's role is both as assistant to the dentist and, where supervision is remote, as his substitute. Producing two types of auxiliaries, one oriented to the dental care of children, mostly preventive, and the second to the curative care of adults, would permit the organization of dental health services on a national priority basis.
RYLANDER, RAGNAR (National Institute of Public Health, Stockholm) : Protective plastic film dressing in smallpox vaccination. Public Health Reports, Vol. 83, September 1968, pp. 787-790.

The objective of this study was to determine the merits of a plastic aerosol, Nobecutan, or Rezifilm, as it is known in the United States, as a dressing for smallpox vaccination sites. The aerosol, which dried as a protective film, was compared with the traditional gauze pad dressing, and special interest was given to the possible effect of the plastic on the number of positive vaccination results.

The percentage of positive results for all 684 vaccinees was 89 percent for 367 persons whose vaccination sites were sprayed with the aerosol and 84 percent for 317 persons whose vaccination sites were dressed with a gauze pad. Application of the plastic film did not exert a negative effect on the number of positive results.

From a practical point of view, the plastic film offered several advantages over the gauze pad dressing, including prevention of secondary pustules on persons sensitive to adhesive tape. 
LEWIS, PAUL M. (Hospital Utilization Project, Pittsburgh, Pa.): The Hospital Utilization Project of Pennsylvania. Public Health Reports, Vol. 83, September 1968, pp. 743-750.

For more than 10 years, western Pennsylvania has seen a logical progression of community-backed efforts to insure quality health care in ways consistent with the public interest. Efforts by medical society officers, supported by hospital administrators and others in the health care field, have provided leadership not only acceptable to the medical professions but recognized as responsible by representatives of industry, government, insurance companies, and the public.

To assist physicians in extending and improving the activities of utilization review committees, the hospital utilization project (H.U.P.) was started in 1963 . H.U.P. abstracts the hospital records of every discharged patient for about $\mathbf{7 5}$ hospitals, using automatic data processing to list cases; prepares comparative statistics ; develops hospital profiles; provides worksheets and sets of diagnostic criteria or guide- lines; and identifies practices and procedures which should be modified.

Each month listings of diagnoses, operations, discharge analyses by service, and deaths are prepared. Semiannually H.U.P. compiles indexes of diagnoses, operations, and pertinent information on diagnoses and care by physicians. The individual statistical reports are distributed to all hospitals. As hospitals are ranked by name, the staff of each hospital can evaluate its position relative to specific hospitals of similar size, clientele, and staff training. Unusual utilization patterns result from a multiplicity of factors, some of which are not within the control of either attending physician or hospital administrators. In surgical cases, prolonged preoperative stays are caused most often by lack of coordination between the admission office and operating room, unavailability of prepaid outpatient diagnostic workups, or inefficient intra- hospital communications that delay laboratory and X-ray studies. Unduly long postoperative stays or delay in discharge of patients are frequently the result of habit or inattention, but are also caused by lack of other appropriate health facilities, particularly for the aged.

The medical society and Blue Cross of Western Pennsylvania sponsored a central review plan to fulfill utilization review requirements for extended care facilities. The 26 participating facilities complete an H.U.P.-designed abstract for each of their patients at the time stays of extended duration are reviewed. The medical society's physician reviewer bases his evaluation for the review committee on the information contained in the abstract.

H.U.P. is completing a comparison of several approved methods of utilization review of extended care facilities. Data on patients of the 26 facilities participating in the central review plan and patients of 12 other facilities using other methods are being analyzed. 